\title{
Influence of particle size distribution on the blast pressure profile from explosives buried in saturated soils
}

\author{
S. E. Rigby ${ }^{1}$ - S. D. Fay ${ }^{2}$ - A. Tyas ${ }^{1}$ - S. D. Clarke ${ }^{1} \cdot$ J. J. Reay ${ }^{2} \cdot$ J. A. Warren ${ }^{1}$. \\ M. Gant ${ }^{3}$. I. Elgy ${ }^{3}$
}

Received: 17 February 2017 / Revised: 10 May 2017 / Accepted: 16 May 2017

(C) The Author(s) 2017. This article is an open access publication

\begin{abstract}
The spatial and temporal distribution of pressure and impulse from explosives buried in saturated cohesive and cohesionless soils has been measured experimentally for the first time. Ten experiments have been conducted at quarterscale, where localised pressure loading was measured using an array of 17 Hopkinson pressure bars. The blast pressure measurements are used in conjunction with high-speed video filmed at 140,000 fps to investigate in detail the physical processes occurring at the loaded face. Two coarse cohesionless soils and one fine cohesive soil were tested: a relatively uniform sand, a well-graded sandy gravel, and a fine-grained clay. The results show that there is a single fundamental loading mechanism when explosives are detonated in saturated soil, invariant of particle size and soil cohesion. It is also shown that variability in localised loading is intrinsically linked to the particle size distribution of the surrounding soil.
\end{abstract}

Keywords Blast - Buried explosive · Hopkinson pressure bar $\cdot$ Particle size distribution · Variability

Communicated by D. Frost.

S. E. Rigby

sam.rigby@shef.ac.uk

1 Department of Civil and Engineering, University of Sheffield, Mappin Street, Sheffield S1 3JD, UK

2 Blastech Ltd., The BioIncubator, 40 Leavygreave Road, Sheffield S3 7RD, UK

3 Physical Sciences Group, DSTL Porton Down, Salisbury, Wiltshire SP4 0JQ, UK

\section{Introduction}

Buried improvised explosive devices (IEDs) and landmines are common throughout areas of conflict. Since the year 1999 there have been almost 100,000 deaths from victim-activated landmines, buried IEDs, cluster munition remnants, and explosive remnants of war worldwide [1]. The widespread prevalence of, and the need to provide engineered systems to adequately protect people and infrastructure against, shallow buried explosives provides a significant challenge to the scientific community.

After an explosive material detonates within a soil, the resultant detonation products violently expand and compact the surrounding soil skeleton. This compacted material spalls from the soil surface at supersonic velocities as the detonation products continue to expand and do work on the soil, generating a complex regime of shock waves propagating through, and interacting with, porous, multiphase media [2]. At some later stage this ejecta cloud may interact with a structure situated at some position above the soil surface and impart a combined blast and impact load. In order to design protective systems to adequately resist the loading arising from buried explosives it is imperative to understand the role that the soil has on the mechanisms and magnitudes of loading in such events.

Previous research into quantification of the output from buried landmines has generally used global impulse as a primary metric [3-9], which by its nature only gives a description of the average loading acting on the target face. Hence, due to the difficulties associated with physically measuring the distribution of loading, little is known about the underlying physics. Consequently, the majority of research into the mechanisms from buried or sand-impact explosions have been informed through interrogation of numerical anal- 
Fig. 1 a Schematic of testing apparatus, $\mathbf{b}$ geometry of test arrangement, c Hopkinson pressure bar arrangement used in the test series (plan view)

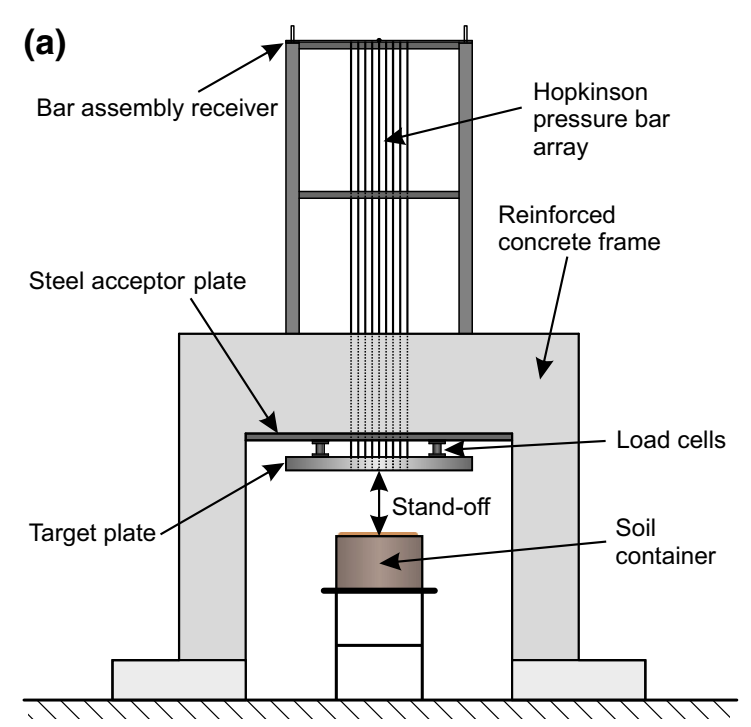

(b)

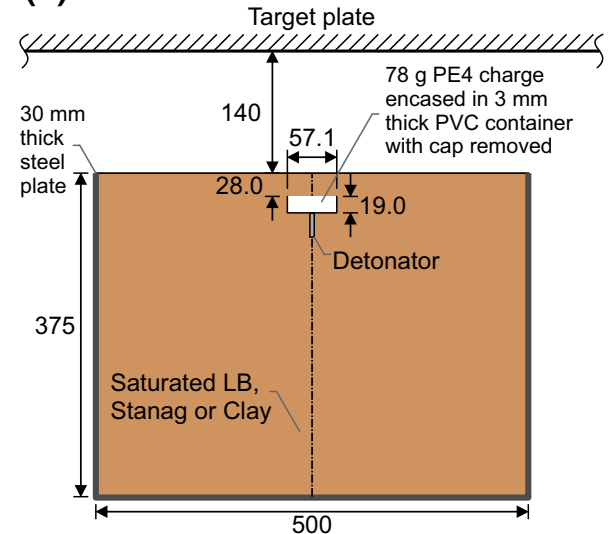

(c)

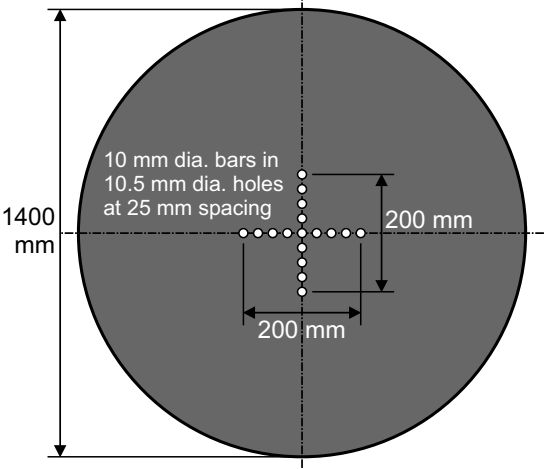

yses [10-13] that remain to be validated or confirmed through experimental observation.

The lack of robust experimentation for measuring the pressure output from buried explosives was initially addressed by small-scale testing conducted at the University of Maryland, USA [14-18], and more recently by quarter-scale testing $[19,20]$, using apparatus developed by the current authors at the University of Sheffield, UK [21]. This paper presents the results from a series of experiments using this apparatus to measure the spatial and temporal variation in loading from saturated soils of different particle size distribution. The general aim of the study is to investigate how the blast load generated after the soil overburden/detonation product mixture impacts a solid target is influenced by the soil properties.

\section{Experimental work}

\subsection{Apparatus}

The apparatus used in the current study is housed at the University of Sheffield explosive testing facility in Buxton,
Derbyshire, UK, and is described in detail in Ref. [21]. The test rig consists of two large, reinforced concrete reaction frames (Fig. 1a), placed approximately $700 \mathrm{~mm}$ apart. A steel container, made from 30-mm-thick steel plate and formed into a 500-mm-diameter, 375-mm-high open-top cylinder (Fig. 1b), sits directly underneath the midpoint of the reaction structure.

The container is filled with soil and a cylindrical; $78 \mathrm{~g}$ PE-4 charge is buried to a depth of $28 \mathrm{~mm}$ measured from the soil surface to the top of the charge, as in Fig. 1b. The charge is encased in a 3-mm-thick PVC container with the cap removed and represents a quarter-scale version of STANAG threat level M2, as given in the Allied Engineering Publication "Procedures for evaluating the protection level of armoured vehicles-mine threat (AEP-55)" [22], which is itself a testing addenda to NATO standardisation agreement, STANAG 4569 [23]. ${ }^{1}$

\footnotetext{
${ }^{1}$ In AEP-55, the full-scale charge is specified as $6 \mathrm{~kg}$ TNT $(94 \mathrm{~g}$ TNT at $1 / 4$ scale). In the current testing programme this has been replaced with PE-4 (5 kg at full-scale, $78 \mathrm{~g} \mathrm{PE}-4$ at $1 / 4$ scale) as recommended in the UK MoD Technical Authority Instructions [24].
} 
A 1400-mm-diameter, 100-mm-thick steel target plate is attached to the underside of the reaction frames (via load cells bolted to the underside of a steel acceptor plate which is cast into the concrete) and spans between them. The centre of the plate is directly aligned with the centre of the soil container, with the face $140 \mathrm{~mm}$ above and parallel to the plane of the top of the soil surface. A series of $10.5 \mathrm{~mm}$ holes are drilled through the thickness of the target plate; four arrays emanate from the plate centre at $25 \mathrm{~mm}$ centre-tocentre spacing, perpendicular and parallel to the span of the plate, with a central hole common to all four arrays (Fig. 1c). The arrays to the left and right of the central hole (in plan) are termed the $-x$ and $+x$ arrays, and those below and above the central hole (in plan) are termed the $-y$ and $+y$ arrays.

Through each of these holes, 10-mm-diameter, 3.25-mlong EN24(T) steel Hopkinson pressure bars (HPBs) [25] are inserted from above. The HPBs are suspended from a receiver frame placed atop the main reaction frame and are machined with threaded distal ends to allow for fine adjustments to their height to ensure that the face of each HPB sits flush with the loaded face of the target plate. Semi-conductor strain gauges are mounted in pairs on the perimeter of each HPB, $250 \mathrm{~mm}$ from the loaded face, in a Wheatstone bridge circuit to ensure that only the axial strain component is recorded. The pressure acting on the face of each bar, and hence the temporal and spatial distribution of the applied load, can be calculated from the recorded axial strain given the elastic modulus of the bar. For this study, 17 HPBs were utilised; one central bar and four arrays of four bars at $25 \mathrm{~mm}$ spacing giving a $200-\mathrm{mm}$ diameter instrumented area in the centre of the target plate.

Strain data were recorded using 14-Bit digital oscilloscopes at a sample rate of $3.125 \mathrm{MHz}$, triggered via a voltage drop in a breakwire embedded in the detonator to synchronise the recordings with the detonation. A Photron SA-Z high-speed video (HSV) camera with a $105 \mathrm{~mm}$ Nikon lens was housed within a protective structure and used to film each test. The events were filmed at a resolution of $1024 \times 184$ at a rate of 140,000 fps and 1/400,000 s exposure time, with an aperture of $f / 2.8$. The camera was positioned level height with the soil surface and was triggered via a separate breakwire embedded in the detonator. Two halogen lights were used to achieve the desired illumination

\subsection{Soil types}

Three different soil types were tested: Leighton Buzzard 14/25 (LB), Stanag soil, and clay. LB is a relatively uniform, rounded to well-rounded quartz silica sand, named after the town in the UK where it is quarried. A grading of 14/25 was specified, giving a range of particle sizes between $0.6-1.18 \mathrm{~mm}$. Stanag soil is a well-graded sandy gravel and is similar to the sandy gravel recommended for use in buried charge tests in AEP-55 [22], and the UK test- ing annexe WP53308 [24]. This soil falls within the basic parameters prescribed in STANAG 4569 [23] from where the soil gets its name. ${ }^{2}$ Speswhite China Clay was also tested, which is a highly refined Kaolin of ultra-fine particle size $(0.5 \%>10 \mu \mathrm{m}$ by mass, $76-83 \%<2 \mu \mathrm{m})$ produced from deposits in the south-west of England [26]. Kaolin is regularly used in the Geotechnical engineering community, and its mechanical behaviour is well documented [27].

Figure 2 shows the particle size distribution (PSD) of the three soils, where the LB and Stanag curves were determined from sieve analysis and the clay curve was taken from the manufacturer's specification, as the majority of the particles are finer than the smallest sieve size. ${ }^{3}$ The coefficient of uniformity of a soil, $C_{\mathrm{u}}$, is given as the effective particle size that $60 \%$ of the soil mass is finer than $\left(D_{60}\right)$, divided by the effective particle size that $10 \%$ of the soil mass is finer than $\left(D_{10}\right)$. The effective particle sizes and coefficients of uniformity of the three soils used are given in Table 1. The values for LB and Stanag were taken directly from the results of the sieve analysis, and the values for clay were taken from the laser diffraction results reported in Ling et al. [28]. Error bars are given on the clay $C_{\mathrm{u}}$ in this study to represent the typical range of values given by Ling et al. for different types of Kaolin.

There is a factor of $\sim 30$ difference between the coefficients of uniformity of LB and Stanag, with clay having intermediate uniformity, and a factor of $\sim 1000$ difference between the typical particle size of clay and Stanag, with LB having intermediate particle size. This will enable the influence of particle size and distribution on the output from shallow buried explosives to be investigated in this study.

Granular materials such as LB and Stanag rely on mechanical interlock from the friction between particles to remain stable and are termed cohesionless. Clay, however, is cohesive and is comprised of interacting charged platelets. This gives clay some tensile load carrying capacity. It is not currently known to what extent the fundamentally different composition of cohesive and cohesionless soils influences the loading mechanisms from buried explosive events. This will also be investigated as part of the current study.

\subsection{Soil preparation and test plan}

\subsubsection{Leighton buzzard and Stanag soil preparation}

The cohesionless soils were mixed dry (typically around $2.5 \%$ moisture content) in a forced action mixer. When thor-

\footnotetext{
${ }^{2}$ In this manuscript, "STANAG" refers to the NATO standardisation agreement, whereas "Stanag" refers to the well-graded sandy gravel used in the current testing.

${ }^{3}$ Mass passing is a term commonly used in geotechnics to denote the relative mass of soil passing through each sieve size following a sieve analysis. In this plot, mass passing gives the percentage of soil particles by mass that are smaller than that particular particle size.
} 


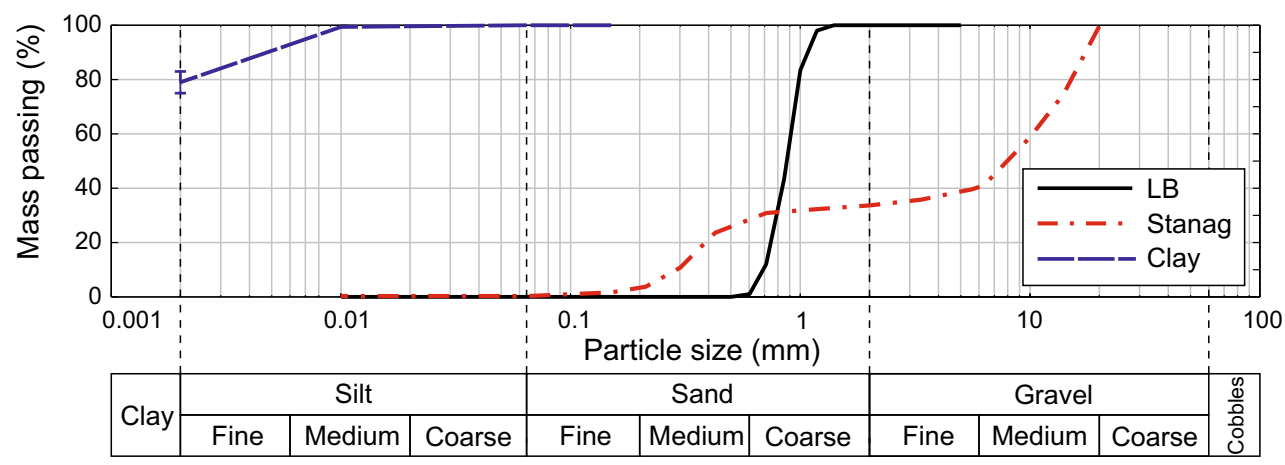

Fig. 2 Particle size distributions of Leighton Buzzard sand (LB) and well-graded sandy gravel (Stanag) from sieve analysis, and Kaolin (Clay) from manufacturer's specification [26]

Table 1 Tabulated $D_{10}$ and $D_{60}$ particle sizes and coefficient of uniformity, $C_{\mathrm{u}}$ for the three soils tested

\begin{tabular}{llll}
\hline Soil & $D_{10}$ & $D_{60}$ & $C_{\mathrm{u}}\left(D_{60} / D_{10}\right)$ \\
\hline Leighton Buzzard 14/25 & $0.699 \mathrm{~mm}$ & $0.904 \mathrm{~mm}$ & 1.293 \\
Stanag soil & $0.292 \mathrm{~mm}$ & $10.27 \mathrm{~mm}$ & 35.19 \\
Kaolin (clay)* & $1.250 \pm 0.1 \mu \mathrm{m}$ & $7.000 \pm 0.5 \mu \mathrm{m}$ & $5.600 \pm 0.9$ \\
\hline
\end{tabular}

* Kaolin properties taken from Ling et al. [28] oughly mixed, the soil was poured and compacted into a steel container (with dimensions shown in Fig. 1b) following the procedure outlined in Rigby et al. [20]. The soil was compacted to a specified dry density in order to achieve the target bulk density when fully saturated. ${ }^{4}$ A length of perforated hose was situated at the bottom of the soil container prior to filling, which enabled the soil to be saturated from the base. This method has been found to achieve a more uniform distribution of moisture content throughout the soil bed and a higher degree of saturation than would be possible from a top-down method [29].

\subsubsection{Clay preparation}

For the cohesive soil tests, $57 \mathrm{~L}$ of water were added to $57 \mathrm{~kg}$ of Speswhite China Clay. This was then mixed to form a slurry and left to soften for 24-48 h to ensure a homogeneous structure with complete saturation. The slurry was poured into a steel container, with the addition of a 300-mm-high, 10-mm-thick, 500-mm-internal-diameter steel collar fixed to the top of the container. A tight seal was ensured between the collar and the container by adding a $30 \mathrm{~mm}$ strip of adhesive bitumen tape. A small amount of compacted Leighton Buzzard was added to the container prior to filling with the slurry to act as a drainage layer. This was separated from the clay using a sintered porous plastic filter (Porvair Vyon F, $2 \mathrm{~mm}$ ). A drainage port was added to the side of the container

${ }^{4} \mathrm{LB}: \rho_{\mathrm{d}}=1.60 \mathrm{Mg} / \mathrm{m}^{3}, \rho=2.00 \mathrm{Mg} / \mathrm{m}^{3}$. Stanag: $\rho_{\mathrm{d}}=1.93 \mathrm{Mg} / \mathrm{m}^{3}$, $\rho=2.20 \mathrm{Mg} / \mathrm{m}^{3}$ due to a naturally lower porosity. Both consistent with previous test series $[29,30]$.

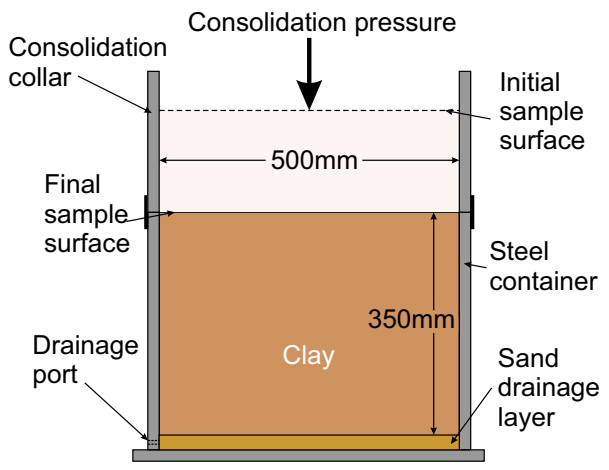

Fig. 3 Schematic of consolidation apparatus

for egress of excess water during the compaction process. A schematic of the consolidation apparatus is shown in Fig. 3.

The clay was then consolidated using a hydraulic press with an internal bore of $80 \mathrm{~mm}$, a stroke length of $500 \mathrm{~mm}$, and a maximum operating pressure of 180 bar. A 498-mmdiameter, 25-mm-thick steel plate was attached to the end of the rod and was surrounded with a bespoke O-ring to ensure a water-tight fit. A constant load of $11.8 \mathrm{kN}$ was applied for $\sim 2$ weeks until the desired consolidation pressure of $72.9 \mathrm{kPa}$ was achieved. The collar was then removed and the container surface levelled. All three Kaolin samples were prepared in parallel to ensure consistency.

For all soil types, the container was sealed in a polythene sheet immediately after filling to prevent the soil from drying. The explosive was buried following the procedure outlined in Rigby et al. [20] immediately prior to testing. 
Table 2 Summary of experimental test plan

\begin{tabular}{llllllll}
\hline Tests & Soil type & $\begin{array}{l}\text { Saturated } \\
\text { bulk density, } \\
\rho\left(\mathrm{Mg} / \mathrm{m}^{3}\right)\end{array}$ & $\begin{array}{l}\text { Burial } \\
\text { depth }(\mathrm{mm})\end{array}$ & Stand-off $(\mathrm{mm})$ & $W$ (g) & Explosive & Shape \\
\hline $1-3$ & Leighton Buzzard 14/25 & 2.00 & 28 & 140 & 78 & PE-4 & $3: 1$ cylinder \\
$4-7$ & Stanag soil & 2.20 & 28 & 140 & 78 & PE-4 & $3: 1$ cylinder \\
$8-10$ & Kaolin (Speswhite China clay) & 1.75 & 28 & 140 & 78 & PE-4 & $3: 1$ cylinder \\
\hline
\end{tabular}

\subsubsection{Test plan}

Ten tests were conducted in total. For all tests, the geometrical set-up was kept identical and only the soil type was changed (Table 2). All soils were tested at full saturation. HSV was not available for tests $1-3$.

\section{Results}

\subsection{Example pressure traces}

Figures 4, 5, and 6 show example pressure-time and impulsetime histories for all 4 HPB arrays from test 1 (LB), test 4 (Stanag), and test 8 (clay), respectively. In each test the central bar $(0 \mathrm{~mm})$ is common to all four arrays and hence appears the same in each of the subplots for a given test. Here, $50 \mu$ s has been subtracted from the time datum of the recorded signals to account for the propagation time of the elastic pulse between the loaded face of the HPB and the strain gauge location. Hence, the results show temporal features of the loading as they occur at the loaded face, enabling synchronisation with the recorded HSV. Correction for Pochhammer-Chree dispersion (e.g. the improved frequency domain method presented in [31]) has not been applied, and the signals are otherwise presented as recorded, with the exception of the time shift. A small amount of spurious oscillations follows the head of the pressure pulses; however, the effect is minimal given the more rounded and longer duration nature of the pulses when compared to the sharp rise associated with free-air shock loading at similar scaled distances [32]. The general form of the pressure-time signals and the total impulse are unaffected by PochhammerChree dispersion.

Generally, there is a high degree of similarity between the form of the imparted loading from the LB tests and clay tests. With the exception of the central bar, which exhibits a sharper rise to peak pressure and more gradual temporal decay afterwards, the bars at 25-100 mm radial offset capture a load that appears to be well rounded with an effectively symmetrical temporal increase to peak pressure and decay back to ambient conditions thereafter. At any instant in time there appears to only be a small area of the target being loaded, with the pressure traces returning to zero shortly after arrival, and passing, of the soil annulus. Qualitatively, there appears to be a good degree of bar-to-bar repeatability for both pressure and impulse, particularly for LB. The form of the pressure history from saturated LB and clay is indicative of the loading mechanism caused by the impact and lateral spreading of a highly pressurised fluid annulus, hypothesised by Grujicic [11] and recently confirmed in our experimental work [19].

The central bar and, to a lesser extent the bars at $25 \mathrm{~mm}$ radial offset, records the presence of a low-pressure ( $\sim 20 \mathrm{MPa}$ ) shoulder that arrives immediately before the primary shock. This is evidence of the pre-cursor shock caused by the initial supersonic expansion of the soil cap above the charge, which effectively acts as a piston; driving the air above the soil and causing a shock to form which reaches the target first [2]. As this pre-cursor shock propagates across the target face it quickly coalesces with the contact surface between the target and the laterally expanding soil surface and is not observed in any bar greater than $25 \mathrm{~mm}$ from the plate centre.

Two main differences are observed between the LB and clay results. Firstly, temporal features such as arrival times and loading durations appear shortened in the clay tests, which may be attributed to the lower bulk density of surrounding soil and therefore greater propensity for lateral flow across the target face. Secondly, the pressure traces appear more variable in clay, with the presence of several low magnitude transients within the main body of the signal. This increased variability will be discussed later, also taking into consideration the Stanag tests.

The Stanag traces appear markedly different from the LB and clay tests. Whilst the underlying form of the loading appears similar and is indeed indicative of a similar loading mechanism (i.e., impact and spreading of a pressurised fluid annulus), there are additional features in the loading which are worth noting. It is clear that the results are: a) more variable in nature than the LB results; and b) the loading for any given bar appears more complex. Whilst the magnitudes are broadly similar to LB/clay in several cases, there are many instances of multiple loading. This results in a steplike impulse history, with the $75 \mathrm{~mm}$ bar in the $-x$ array offering a clear example (the first subplot in Fig. 5). Here, there is a small magnitude load acting between $0.25-0.3 \mathrm{~ms}$, 

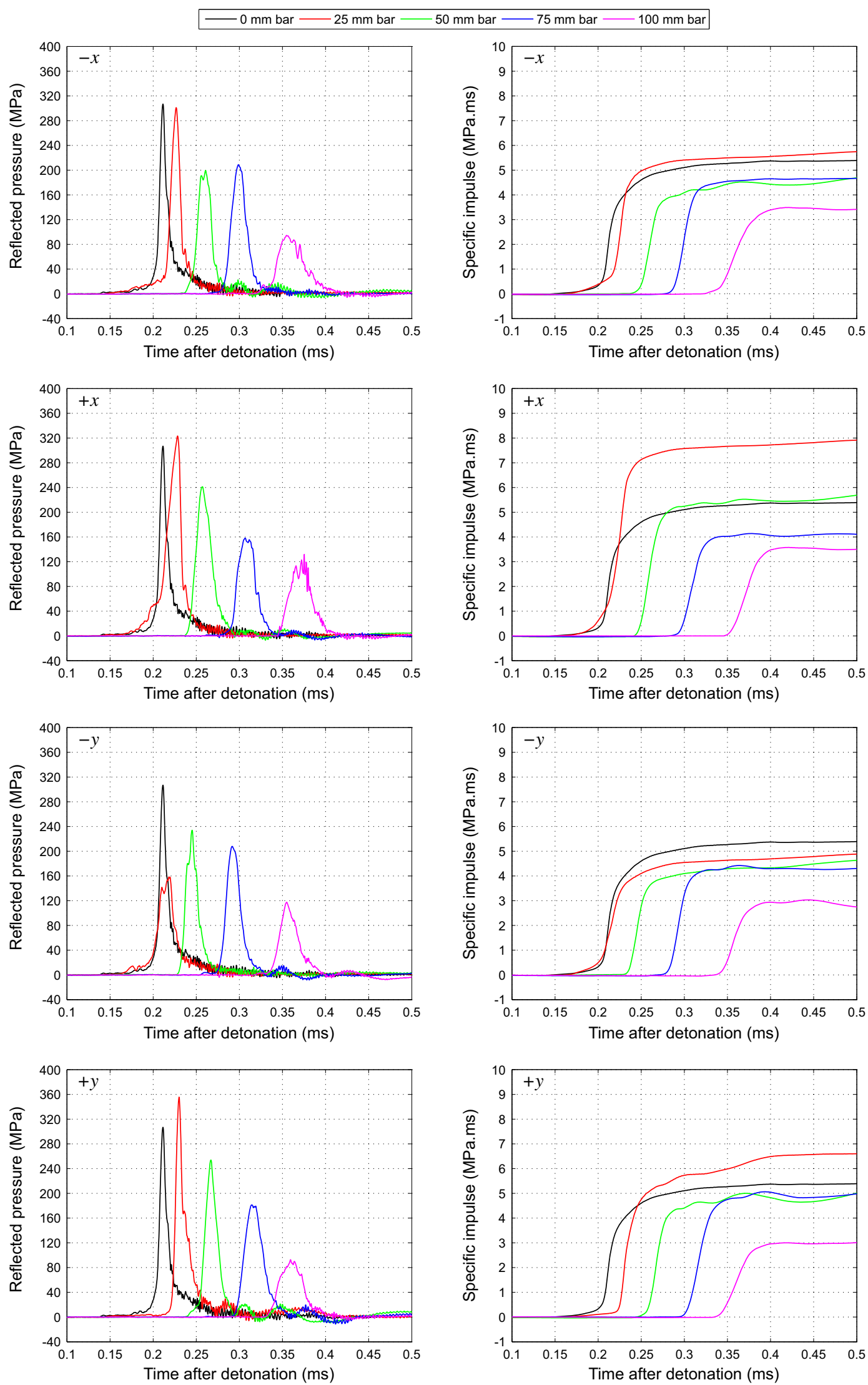

Fig. 4 Example pressure-time and impulse-time histories for test 1; Leighton Buzzard 


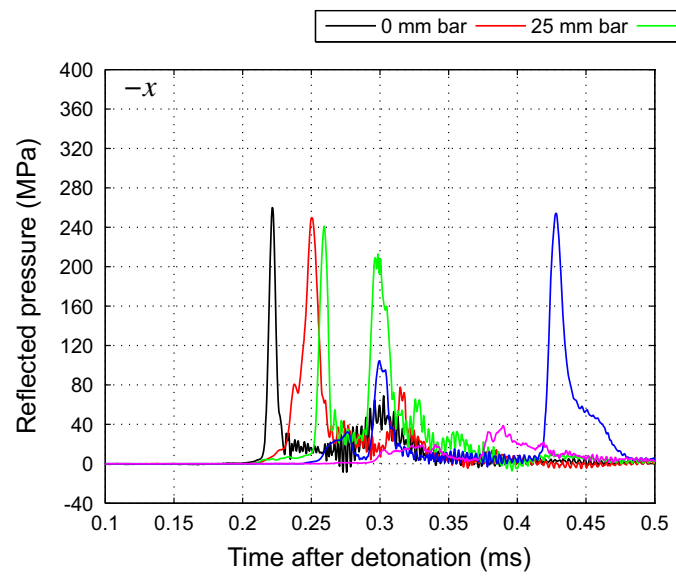

$50 \mathrm{~mm}$ bar $-75 \mathrm{~mm}$ bar $-100 \mathrm{~mm}$ bar
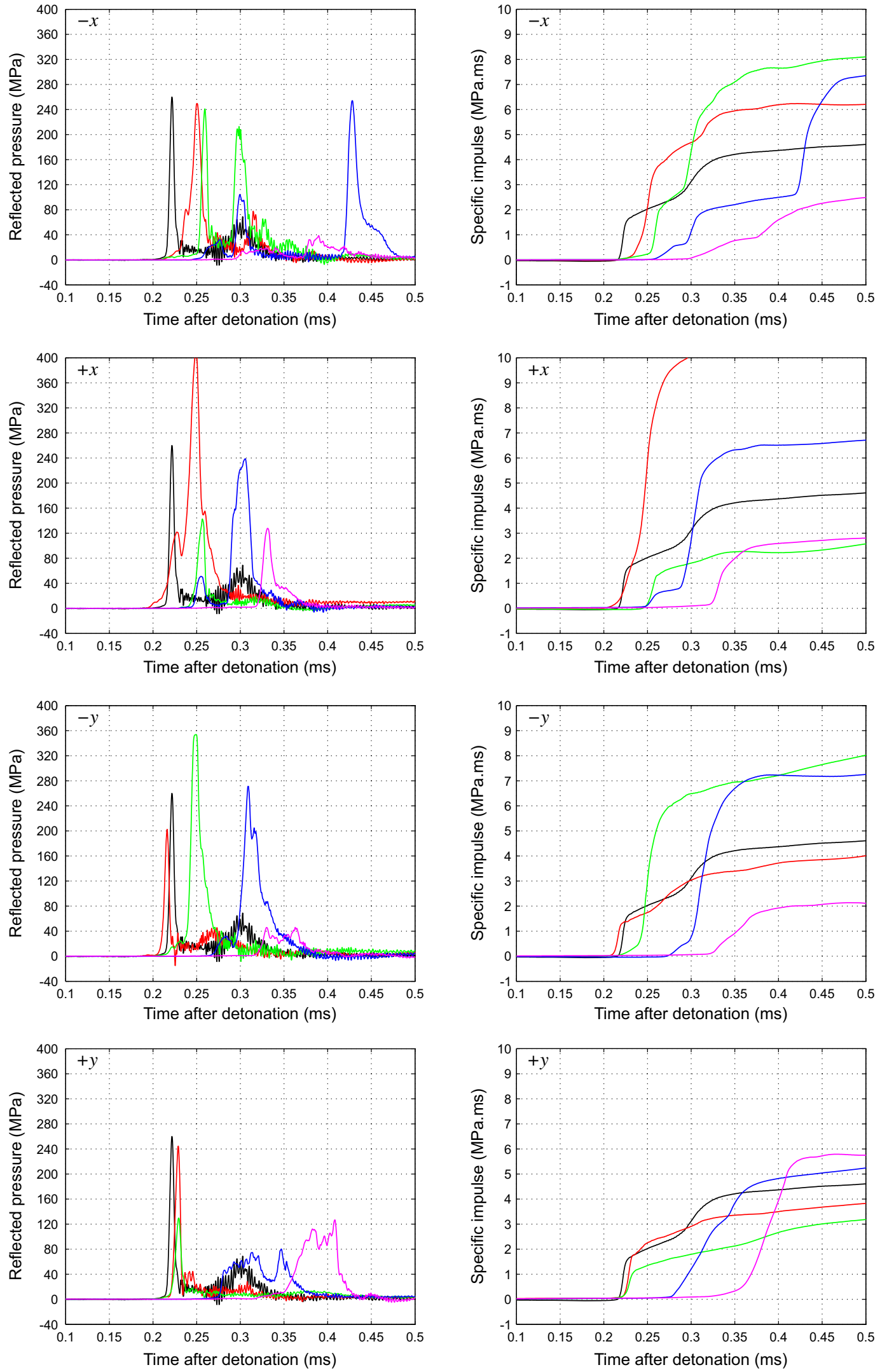

Fig. 5 Example pressure-time and impulse-time histories for test 4; Stanag soil 

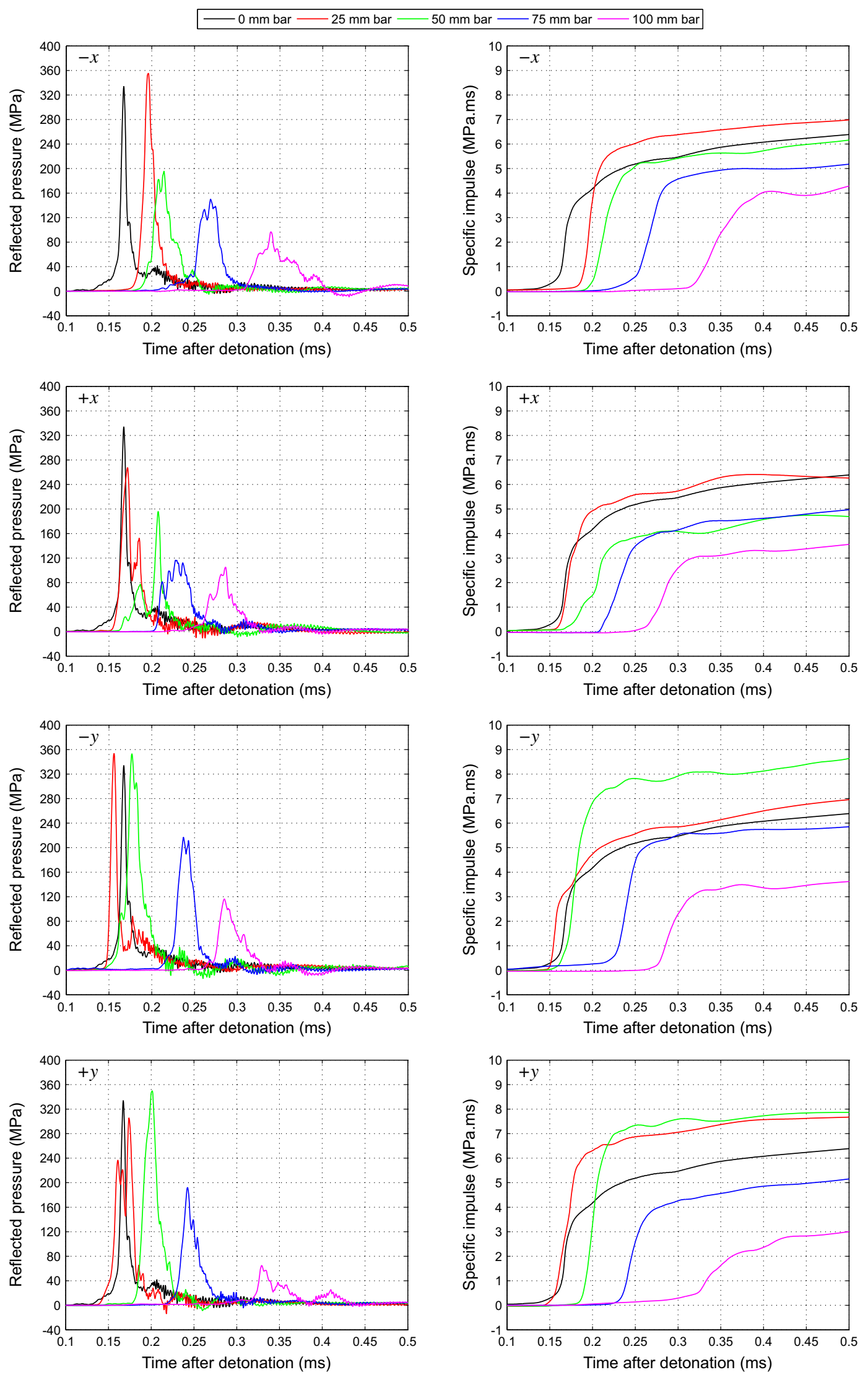

Fig. 6 Example pressure-time and impulse-time histories for test 8; clay 

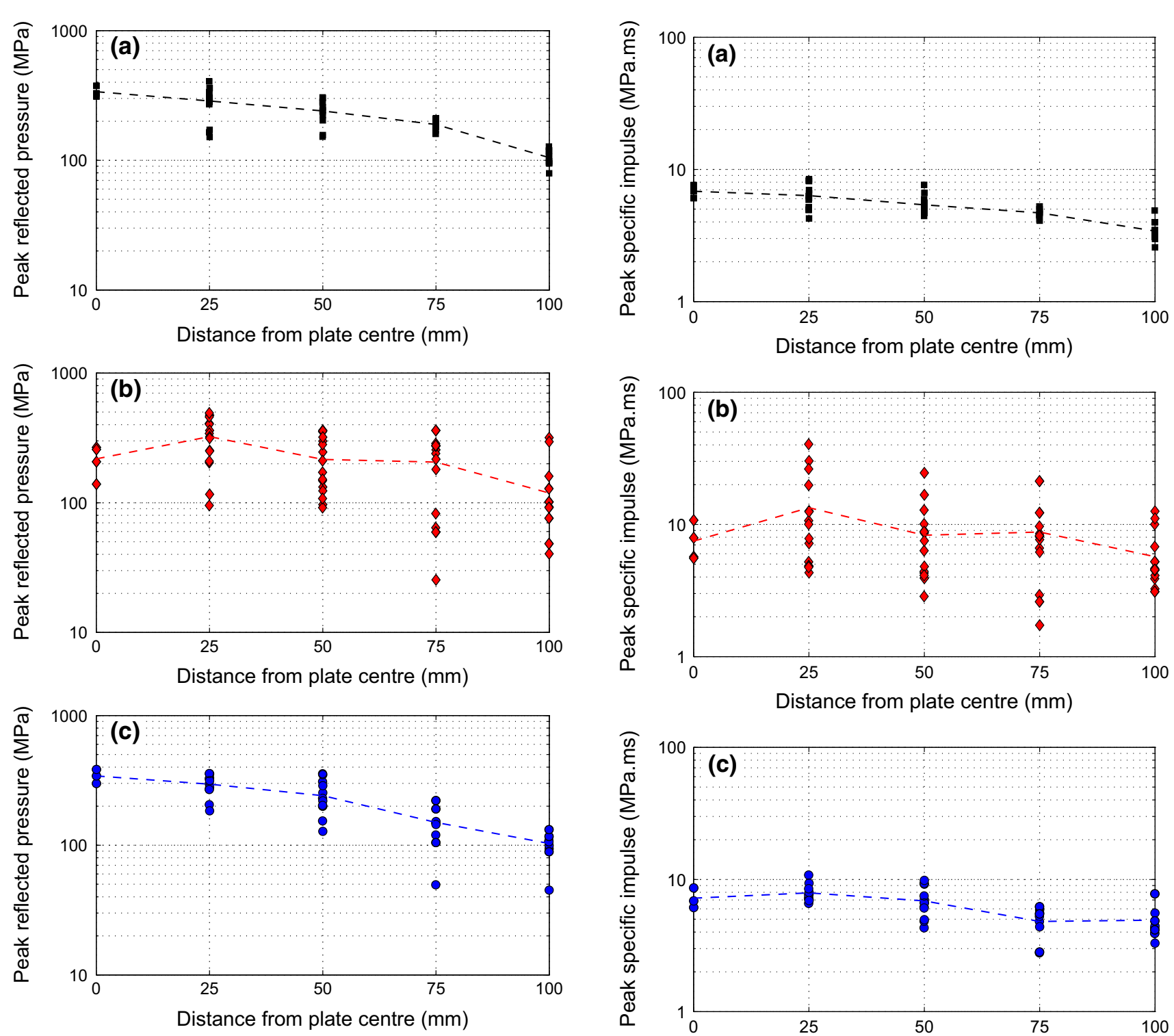

Fig. 7 Compiled peak reflected pressure: a LB, b Stanag, c clay
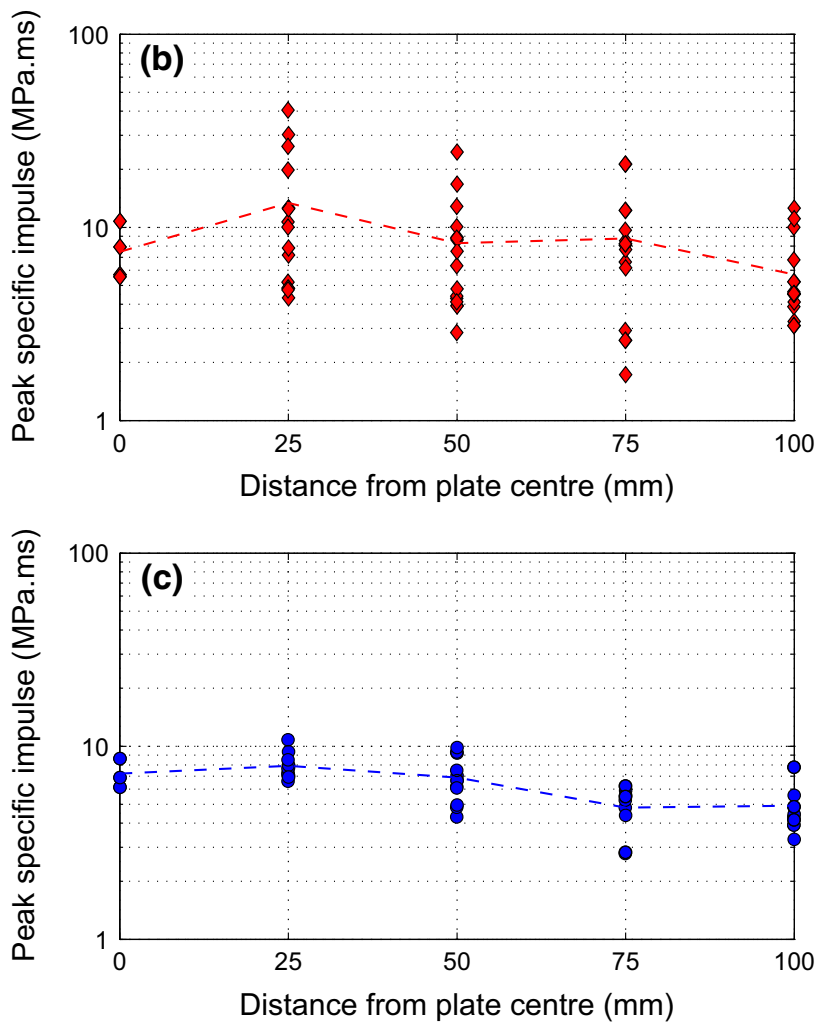

Fig. 8 Compiled peak-specific impulse: a LB, b Stanag, c clay

immediately followed by a secondary larger magnitude load, each imparting approximately 0.6 and $2.0 \mathrm{MPa}$ ms of specific impulse, respectively. At around $0.42 \mathrm{~ms}$ after detonation there is a final phase of loading, equal in peak pressure magnitude and greater in specific impulse than the total loading on the central bar.

It has been shown, therefore, that the presence of a wellgraded distribution of particle size within a soil (at the quarter-scale testing of the current study) causes a more complex and more stochastic loading distribution to develop on the loaded face when compared to tests conducted with more uniform soils, i.e., LB and clay. Note that the largest particles in Stanag are up to twice the diameter of the recording HPBs rather than an order of magnitude smaller as with LB.

\subsection{Compiled results}

Figures 7 and 8 show the peak pressure and peak-specific impulse, respectively, for all tests, compiled for each individual soil type and plotted against distance from the plate centre. The mean peak pressures and mean peak-specific impulses have been calculated for each soil type at 0,25 , 50,75 , and $100 \mathrm{~mm}$ from the plate centre and are shown in Table 3. The mean pressure/impulse at each radial ordinate is given by the dashed line in Figs. 7 and 8 .

The LB and clay results occupy a narrow band either side of the mean, whereas the Stanag results show an increased spread. The relative standard deviation (RSD) is given as the standard deviation divided by the mean and can be used 
Table 3 Compiled peak pressure and peak-specific impulse for LB, Stanag soil and clay

\begin{tabular}{|c|c|c|c|c|c|c|}
\hline \multirow[t]{2}{*}{ Soil } & \multirow[t]{2}{*}{ Bar location (mm) } & \multirow[t]{2}{*}{ Number of data points } & \multicolumn{2}{|l|}{$\underline{\text { Peak pressure }}$} & \multicolumn{2}{|c|}{ Peak-specific impulse } \\
\hline & & & Mean (MPa) & $\mathrm{RSD}(\%)$ & Mean (MPa ms) & $\operatorname{RSD}(\%)$ \\
\hline \multirow[t]{6}{*}{ Leighton Buzzard } & 0 & 3 & 337.9 & 9.87 & 6.823 & 11.2 \\
\hline & 25 & 12 & 286.2 & 29.1 & 6.326 & 22.1 \\
\hline & 50 & 12 & 239.9 & 21.0 & 5.392 & 17.6 \\
\hline & 75 & 12 & 188.8 & 8.24 & 4.689 & 7.82 \\
\hline & 100 & 12 & 104.7 & 13.2 & 3.410 & 18.0 \\
\hline & & & Weighted RSD & 17.4 & Weighted RSD & 16.1 \\
\hline \multirow[t]{6}{*}{ Stanag soil } & 0 & 4 & 217.7 & 26.9 & 7.475 & 32.6 \\
\hline & 25 & 16 & 323.4 & 39.1 & 13.39 & 79.2 \\
\hline & 50 & 16 & 215.8 & 46.5 & 8.291 & 69.1 \\
\hline & 75 & 16 & 205.7 & 54.5 & 8.750 & 66.6 \\
\hline & 100 & 16 & 118.7 & 67.2 & 5.693 & 51.5 \\
\hline & & & Weighted RSD & 50.4 & Weighted RSD & 64.6 \\
\hline \multirow[t]{6}{*}{ Kaolin (clay) } & 0 & 3 & 341.6 & 12.4 & 7.220 & 17.7 \\
\hline & 25 & 12 & 295.2 & 19.3 & 7.911 & 15.0 \\
\hline & 50 & 12 & 240.8 & 30.1 & 6.884 & 26.5 \\
\hline & 75 & 12 & 149.7 & 34.0 & 4.817 & 27.3 \\
\hline & 100 & 12 & 102.9 & 22.6 & 4.922 & 29.6 \\
\hline & & & Weighted RSD & 25.7 & Weighted RSD & 24.2 \\
\hline
\end{tabular}

Mean and relative standard deviation (RSD) calculated at each bar location

to describe the repeatability of pressure and impulse measurements at each location on the target, under different soil conditions. RSDs were evaluated for peak pressure and peakspecific impulse at each bar location for each soil type and are also shown in Table 3. Here, the weighted RSD is given as the average of the RSDs for a particular soil type, weighted by the number of data points at that bar location.

\section{Discussion}

\subsection{Loading distribution}

The mean peak pressure distribution is broadly similar for all soils, with the peak pressure varying from over $300 \mathrm{MPa}$ in the bars above the charge (0-25 mm), to approximately $100 \mathrm{MPa}$ at $100 \mathrm{~mm}$ from the plate centre. The form of the LB and clay specific impulse distributions is generally similar, with both soils generating a loading that decays gradually with distance from the plate centre. In both cases the mean of the peak specific impulse recorded at the $100 \mathrm{~mm}$ bar locations is between $54 \%$ (LB) and $62 \%$ (clay) of the mean of the peak specific impulse recorded at the $25 \mathrm{~mm}$ bar locations. ${ }^{5} \mathrm{In}$ contrast, the Stanag specific impulse appears more uniformly

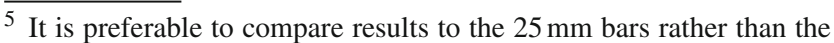
central bar because of the greater number of data points.
}

distributed (accounting for the spread of data), with the specific impulse increasing from 7.5 MPa ms at the central bar to $8.8 \mathrm{MPa} \mathrm{ms}$ at the $75 \mathrm{~mm}$ bar location, and subsequently decaying to $5.7 \mathrm{MPa} \mathrm{ms}$ at the $100 \mathrm{~mm}$ bar location. Interestingly, the magnitude of the mean peak specific impulse at the $100 \mathrm{~mm}$ bar location is only $43 \%$ of that at the $25 \mathrm{~mm}$ bar location.

Table 4 gives the total impulse recorded for each test over the central $100 \mathrm{~mm}$ radius region, calculated by integrating the linear distribution of test-averaged impulse at each radial ordinate with respect to area. Also given are the RSDs of the area-integrated impulses. Whilst this parameter is only calculated from 3 to 4 tests per soil type, it can be used to make indicative comments on the repeatability of the test data when it has been distributed over the whole instrumented region. Here, two mean area-integrated impulses and associated RSDs have been calculated for Stanag; one pair using the entire dataset and one pair omitting the data from test 6 , as the impulse in this test appears to have been substantially increased by several large discrete particle strikes that may not be indicative of the loading across the whole instrumented region.

In the LB and clay tests, momentum is primarily transferred to the target through lateral flow of the expanding pressurised soil annulus [11]. Whilst this mechanism is still present in the Stanag tests, there appears to be an additional momentum transfer from discrete particle strikes (separate 
Table 4 Area-integrated impulse (to $100 \mathrm{~mm}$ radius) for all tests

\begin{tabular}{lll}
\hline Soil & Test number & Area-integrated impulse (Ns) \\
\hline Leighton Buzzard & 1 & 144.7 \\
& 2 & 155.5 \\
& 3 & 145.9 \\
& & Mean: 148.7 \\
Stanag soil & 4 & RSD: $3.98 \%$ \\
& 5 & 213.1 \\
& 6 & 219.9 \\
& 7 & 352.8 \\
Kaolin (clay) & 8 & 261.5 \\
& 9 & Mean: $261.8 / 231.5^{*}$ \\
& 10 & 168.3 \\
& & 188.1 \\
& & 179.8 \\
& & Mean: 178.7 \\
& & RSD: $5.56 \%$
\end{tabular}

* Denotes mean and RSD with test 6 omitted

from the main soil annulus) from some of the larger soil particles situated above the charge. The momentum initially imparted to these particles from the explosion has a high velocity component normal to the soil surface, with little velocity perpendicular to the soil surface. Hence, these particles are more likely to strike the target in the area above the charge. It is hypothesised, therefore, that whilst the LB and clay impulse decays gradually from the charge centre, the Stanag impulse distribution is higher in magnitude towards the centre, but decays rapidly outside of the region of regular particle strikes, as in Fig. 9. This region appears to be between the 75 and $100 \mathrm{~mm}$ bar locations in our testing (i.e., between 2.6 and 3.5 charge radii from the centre); however, this is an observation based on limited test results at quarter-scale, and hence, more testing is required to either confirm or deny the limits of this region.

This hypothesis is supported by observations from the half-scale experimental results reported by Clarke et al. [30]. Here, total impulse and peak deflection were measured using $675 \mathrm{~mm}$ square plates, i.e., representing an instrumented region extending to $168.75 \mathrm{~mm}$ from the charge centre at this scale. The ratio between the measured impulses of LB:Stanag:clay (all saturated) was 1.00:0.84:1.25, when compared to 1.00:1.56:1.20 determined from the current testing (Table 4). As the clay impulse is $20-25 \%$ greater than LB in both test series, this suggests that the distribution of impulse is similar for both target sizes, however that the Stanag is $56 \%$ greater than LB over a $100 \mathrm{~mm}$ radius yet falls to $16 \%$ less when considering a $337.5 \mathrm{~mm}$ square plate (at quarter-scale) demonstrates that the impulse distribution is

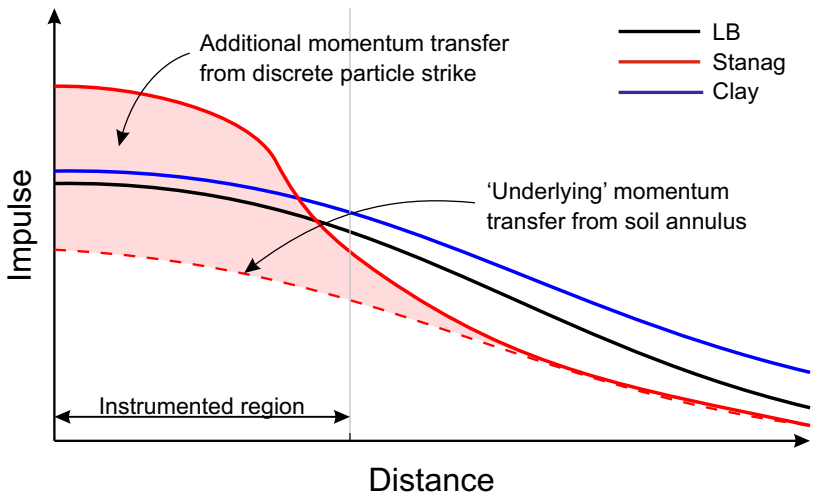

Fig. 9 Hypothesised impulse distributions outside of instrumented region

more heavily weighted towards the target centre when using Stanag. As the Stanag soil is the stiffest of the three soils tested, there will also be an increased natural directionality in these tests.

The deflection measurements in Ref. [30] support this: there was no discernible difference between central peak displacement when using LB and Stanag despite the Stanag imparting a lower impulse, again suggesting a more centralised loading distribution from Stanag soil.

\subsection{Localised variability}

Previous sections in this article, as well as other studies in the literature, have demonstrated that the output from shallow buried explosives is dependent on the soil type. In the following section we will demonstrate the effect that particle size distribution has on localised variations in blast pressure from buried explosives.

The RSDs in Tables 3 and 4 demonstrate the influence of soil type on both localised and global variability, with Stanag soil being the least repeatable and LB the most. These findings are supported by results in Ref. [29], which argue that the observed variability is a feature of the loading generated itself, as there was no correlation between variability in loading output and the ability to accurately prepare the soil to specified geotechnical conditions. Inspection of HSV footage (Figs. 10, 11 for Stanag and clay, respectively) reveals some features which corroborate this hypothesis.

When the detonation wave reaches the surface of the soil, it is largely reflected back into the soil skeleton as a tensile wave. Combined with the vertical force exerted to the soil from the high-pressure detonation products, this causes a soil cap to be ejected from the surface of the soil at supersonic velocity [2]. In Stanag soil there is a large range of particle sizes situated above the charge. Some smaller particles can be seen to pick up a higher velocity and escape ahead of the main body of the soil ejecta $(0.10-0.16 \mathrm{~ms}$ after detonation 

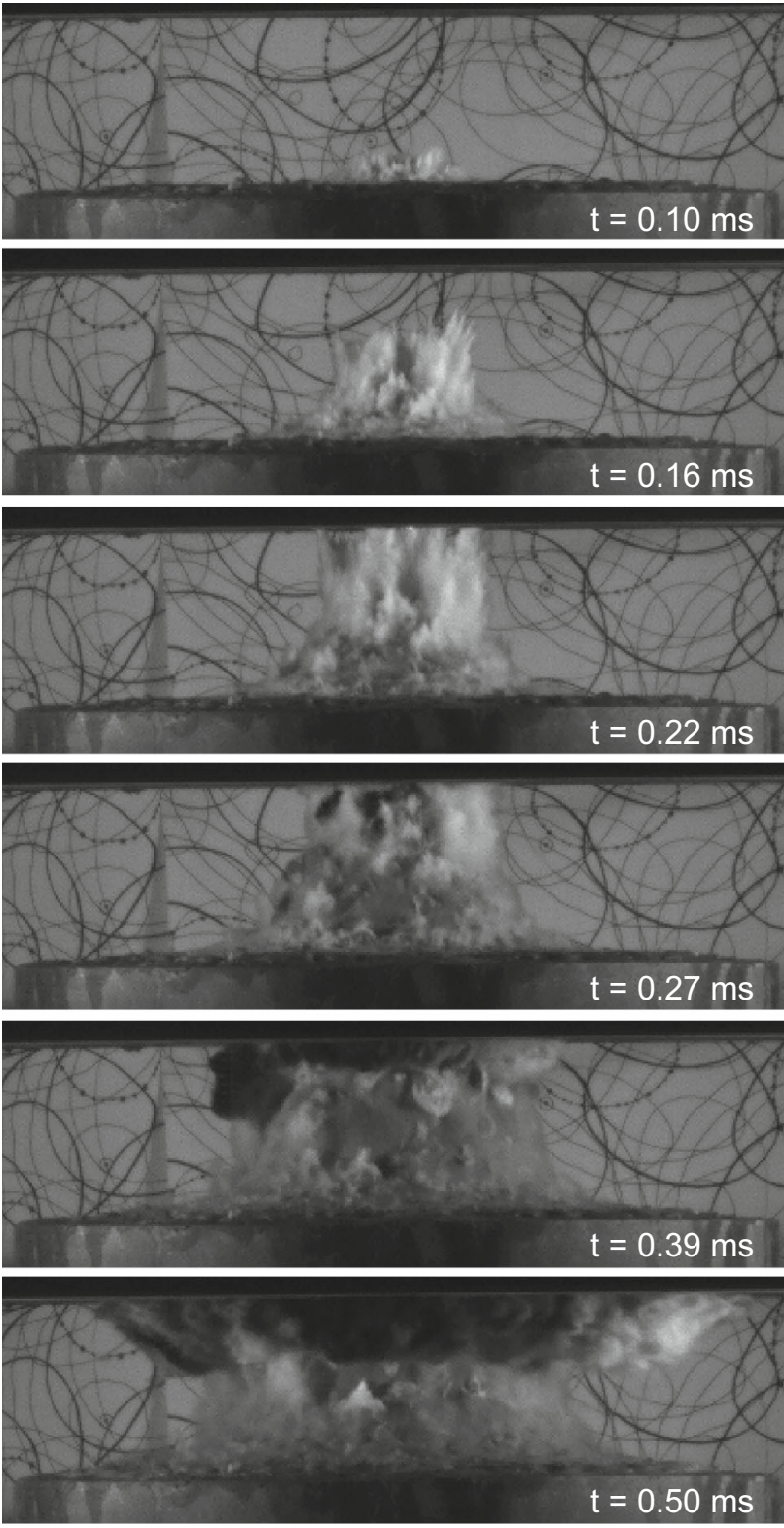

Fig. 10 HSV stills from test 4; Stanag soil

in Fig. 10). Whilst these particles are likely to impart some momentum to the target, their significance is largely that they give rise to preferential paths for the detonation products to vent (this can be seen beginning at $0.27 \mathrm{~ms}$ with a particularly prominent emergence of the detonation products on the lefthand field of view at $0.39 \mathrm{~ms}$ after detonation in Fig. 10). This gives rise to a late-time complex regime of expanding detonation product gasses interacting with the still-expanding soil annulus. It is suggested that the loading in this region will more closely resemble the combined air shock/soil impact loading observed in dry tests, once the soil bubble has lost its structure [20]; however, this lies outside the instrumented region in the current testing. We see evidence of this trend
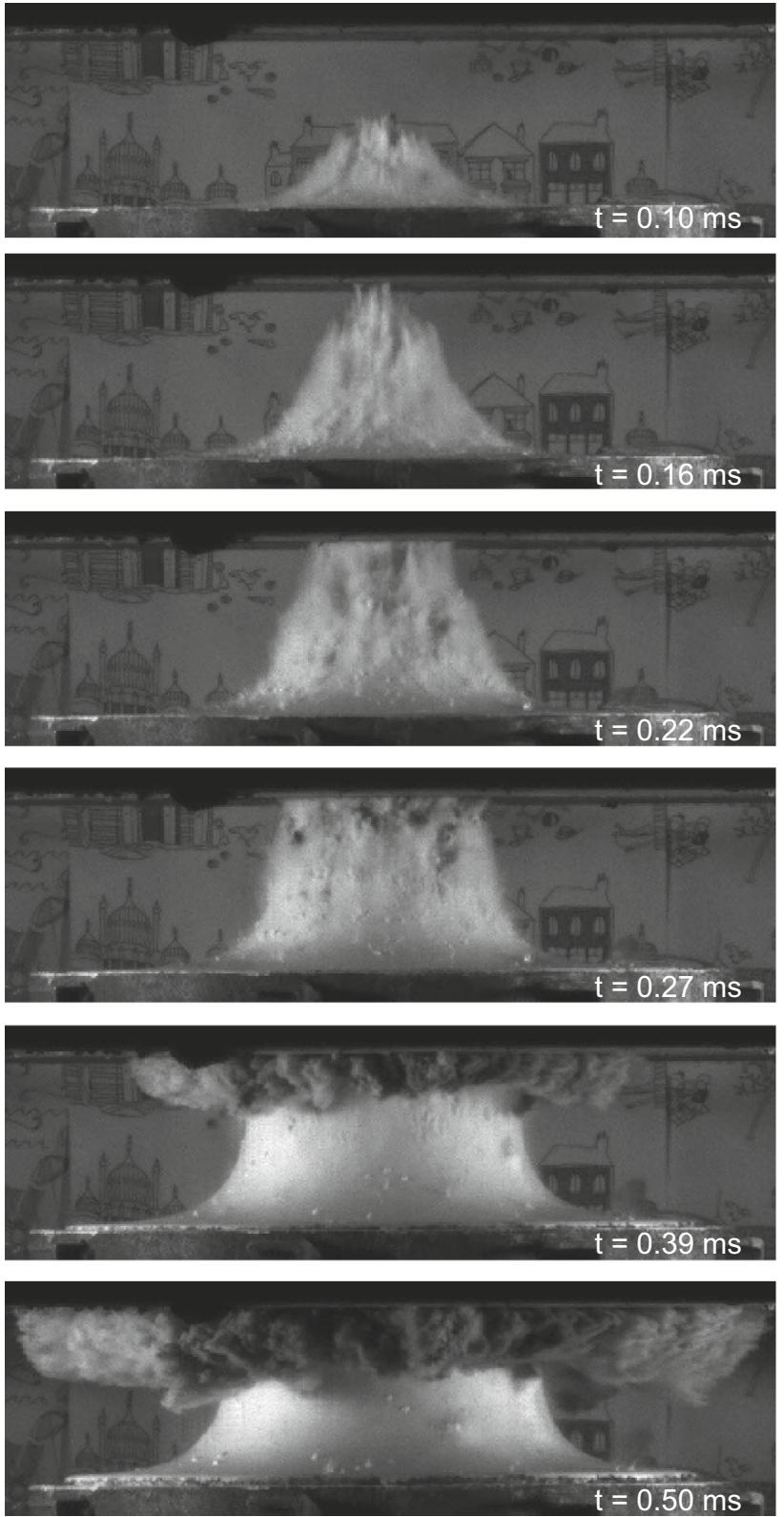

Fig. 11 HSV stills from test 8; clay

beginning, with an observed increase in variability (RSD) with distance from the plate centre in the Stanag tests.

The ejected soil cap in the clay tests, in contrast, is largely homogeneous (i.e., of uniform particle size). In Fig. 11 some fines are observed ahead of the main soil bubble, but overall the expanding soil annulus is more uniform and symmetrical, for example at $0.22 \mathrm{~ms}$ after detonation compared to $0.27 \mathrm{~ms}$ after detonation in the Stanag HSV stills (when the main loading has approximately reached the $50 \mathrm{~mm}$ bar location in both cases). As the clay annulus expands it maintains its integrity until the contact interface between the clay and target has passed the $100 \mathrm{~mm}$ bar location (between 0.27 and $0.39 \mathrm{~ms}$ after detonation), where the soil bubble has suffi- 


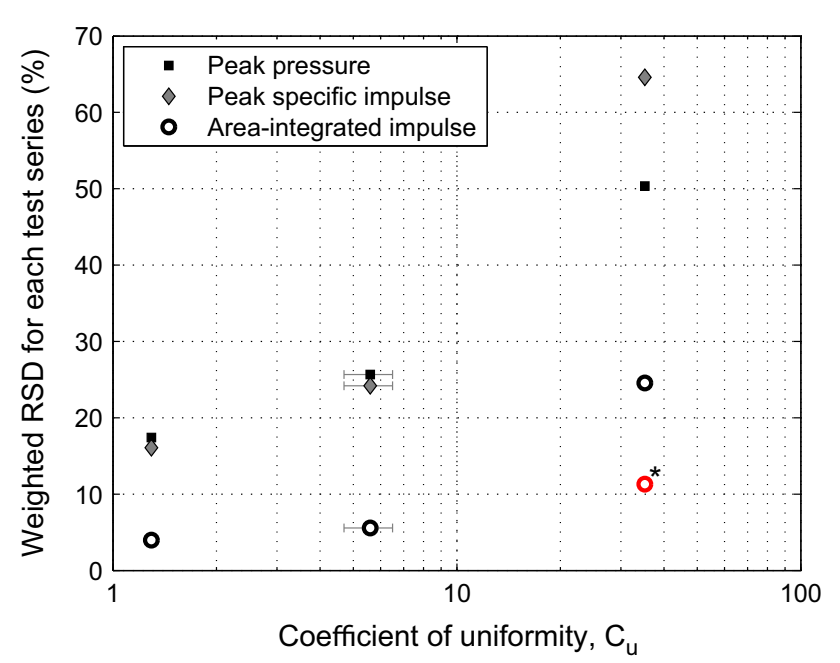

Fig. 12 Statistical variation of peak pressure, peak-specific impulse, and area-integrated impulse, plotted against soil's coefficient of uniformity (Table 1$). *$ denotes test 6 area-integrated impulse omitted

ciently thinned so as to cause shear failure within the soil skeleton and venting of the detonation products. Whilst no HSV is available for LB, it is clear from comparison of the loading signals (Figs. 4, 6) that the behaviour will be nearidentical to clay until the soil bubble passes outside of the instrumented region of the plate.

Figure 12 shows the weighted RSDs from Tables 3 and 4 plotted against the coefficient of uniformity (Table 1) of each soil. It is clear that the repeatability of the output from a shallow buried explosive is directly related to a measure of uniformity of the surrounding soil particles. This figure also shows that the area-integrated impulse demonstrates considerably less spread than the localised peak pressure and specific impulse measurements. It is observed that, (with the exception of test 6), whilst a given test may demonstrate considerable localised effects, these localised variations are typically not borne out in area-integrated impulse. Therefore, the apparatus described herein can be used to study both local and global effects without any loss in accuracy.

\section{Summary and conclusions}

Ten tests were conducted at quarter-scale using three different soils, with orders of magnitude difference between the uniformity and particle size of each: a relatively uniform sand (Leighton Buzzard); a well-graded sandy gravel (Stanag); and clay. Tests were conducted using a bespoke apparatus which utilises Hopkinson pressure bars flush-mounted through the thickness of a nominally rigid target. Therefore, this allows the spatial and temporal distribution of pressure and impulse from explosives buried in saturated clays and soils to be measured experimentally.
The results and associated high-speed video footage have demonstrated:

- No fundamental difference in loading mechanisms between cohesive and cohesionless soils

- Particle size has no significant affect on loading mechanism

- Localised variations in loading are inversely proportional to uniformity of the soil

- A well-graded soil (with particles over $10 \mathrm{~mm}$ ) will demonstrate considerable localised particle strikes in the region directly above the charge which gives rise to a more centralised loading distribution when compared to more uniform soils

Data access statement The data presented in this publication can be obtained on request by contacting sam.rigby@sheffield.ac.uk.

Acknowledgements The authors wish to thank the Defence Science and Technology Laboratory for funding the published work, and technical staff at Blastech Ltd. for their assistance in conducting the experimental work reported herein.

Open Access This article is distributed under the terms of the Creative Commons Attribution 4.0 International License (http://creativecomm ons.org/licenses/by/4.0/), which permits unrestricted use, distribution, and reproduction in any medium, provided you give appropriate credit to the original author(s) and the source, provide a link to the Creative Commons license, and indicate if changes were made.

\section{References}

1. International Campaign to Ban Landmines-Cluster Munition Coalition. Landmine Monitor. http://www.the-monitor.org/media/ 2152583/Landmine-Monitor-2015_finalpdf.pdf (2015). Accessed 28 Apr 2017

2. Bergeron, D., Walker, R., Coffey, C.: Detonation of 100-gram antipersonnel mine surrogate charges in sand-a test case for computer code validation. Technical Report 668, Defence Research Establishment Suffield, Ralston, Alberta, Canada (1998)

3. Bergeron, D.M., Tremblay, J.E.: Canadian research to characterize mine blast output. In: Proceedings of the 16th International Symposium on the Military Aspects of Blast and Shock, Oxford, UK, pp. 501-511 (2000)

4. Hlady, S.L.: Effect of soil parameters on landmine blast. In: Proceedings of the 18th International Symposium on the Military Aspects of Blast and Shock (MABS18), Bad Reichenhall, Germany (2004)

5. Fourney, W.L., Leiste, U., Bonenberger, R., Goodings, D.J.: Mechanism of loading on plates due to explosive detonation. Fragblast Int. J. Blasting Fragm. 9, 205-217 (2005). doi:10.1080/ 13855140500431989

6. Anderson, C.E., Behner, T., Weiss, C.E.: Mine blast loading experiments. Int. J. Impact Eng. 38, 697-706 (2011). doi:10.1016/j. ijimpeng.2011.04.005

7. Fox, D.M., Huang, X., Jung, D., Fourney, W.L., Leiste, U., Lee, J.S.: The response of small scale rigid targets to shallow buried explosive detonations. Int. J. Impact Eng. 38, 882-891 (2011). doi:10.1016/ j.ijimpeng.2011.05.009 
8. Ehrgott, J.Q., Rhett, R.G., Akers, S.A., Rickman, D.D.: Design and fabrication of an impulse measurement device to quantify the blast environment from a near-surface detonation in soil. Exp. Tech. 35, 51-62 (2011). doi:10.1111/j.1747-1567.2009.00604.X

9. Fox, D.M., Akers, S.A., Leiste, U.H., Fourney, W.L., Windham, J.E., Lee, J.S., Ehrgott, J.Q., Taylor, L.C.: The effects of air filled voids and water content on the momentum transferred from a shallow buried explosive to a rigid target. In. J. Impact Eng. 69, 182-193 (2014). doi:10.1016/j.ijimpeng.2014.02.019

10. Grujicic, M., Pandurangan, B., Cheeseman, B.A.: The effect of degree of saturation of sand on detonation phenomena associated with shallow-buried and ground-laid mines. Shock Vib. 12, 1-21 (2008). doi:10.1155/2006/652405

11. Grujicic, M., Pandurangan, B.: A combined multi-material Euler/Lagrange computational analysis of blast loading resulting from detonation of buried landmines. Multidiscip. Model. Mater. Struct. 4(2), 105-124 (2008). doi:10.1163/157361108784050086

12. Deshpande, V.S., McMeeking, R.M., Wadley, H.N.G., Evans, A.G.: Constitutive model for predicting dynamic interactions between soil ejecta and structural panels. J. Mech. Phys. Solids 57(8), 11391164 (2009). doi:10.1016/j.jmps.2009.05.001

13. Børvik, T., Olovsson, L., Hanssen, A.G., Dharmasena, K.P., Hansson, H., Wadley, H.N.G.: A discrete particle approach to simulate the combined effect of blast and sand impact loading of steel plates. J. Mech. Phys. Solids 59(5), 940-958 (2011). doi:10.1016/j.jmps. 2011.03.004

14. Taylor, L.C., Fourney, W.L., Leiste, U., Cheeseman, B.: Loading mechanisms on a target from detonation of a buried charge. In: Proceedings of the 24th International Symposium on Ballistics, New Orleans, USA (2008)

15. Fourney, W.L., Leiste, U., Taylor, L.C.: Pressure irregularities in the loading of vehicles by buried mines. In: Proceedings of the 34th Annual Conference on Explosives and Blasting Technique, Cleveland, Ohio, USA (2008)

16. Taylor, L.C., Fourney, W.L., Leiste, H.U.: Pressures on targets from buried explosions. Blasting Fragm. 4(3), 165-192 (2010)

17. Leiste, H.U.: Experimental studies to investigate pressure loading on target plates. $\mathrm{PhD}$ thesis, Department of Mechanical Engineering, University of Maryland, USA (2012)

18. Leiste, H.U., Fourney, W.L., Duff, T.: Experimental studies to investigate pressure loading on target plates. Blasting Fragm. 7(2), 99-126 (2013)

19. Clarke, S.D., Rigby, S.E., Fay, S.D., Tyas, A., Reay, J.J., Warren, J.A., Gant, M., Livesey, R., Elgy, I.: 'Bubble-type' vs 'shock-type' loading from buried explosives. In: Proceedings of the 16th International Symposium on Interaction of the Effects of Munitions with Structures (ISIEMS16), Florida, USA (2015)

20. Rigby, S.E., Fay, S.D., Clarke, S.D., Tyas, A., Reay, J.J., Warren, J.A., Gant, M., Elgy, I.: Measuring spatial pressure distribution from explosives buried in dry Leighton Buzzard sand. Int. J. Impact Eng. 96, 89-104 (2016). doi:10.1016/j.ijimpeng.2016.05.004
21. Clarke, S.D., Fay, S.D., Warren, J.A., Tyas, A., Rigby, S.E., Elgy, I.: A large scale experimental approach to the measurement of spatially and temporally localised loading from the detonation of shallow-buried explosives. Meas. Sci. Technol. 26, 015001 (2015). doi:10.1088/0957-0233/26/1/015001

22. Procedures for Evaluating the Protection Level of Armoured Vehicles-Mine Threat, vol. 2, C edn. Allied Engineering Publication (AEP) 55 (2014)

23. NATO: Protection Levels for Occupants of Armoured Vehicles, 3rd edn. STANAG 4569 (2014)

24. Elgy, I.D., Gant, M.T.A., Gibson, C.S., Livesey, R.J., Normand, M.C., Taylor, R., Williams, G.H.: UK Ministry of Defence Technical Authority Instructions for Testing the Protection Level of Vehicles Against Buried Blast Mines. Defence Science and Technology Laboratory, Salisbury (2014)

25. Hopkinson, B.: A method of measuring the pressure produced in the detonation of high explosives or by the impact of bullets. Philios. Trans. R. Soc. Lond. Ser. A Contain. Pap. Math. Phys. Character 213(1914), 437-456 (1914)

26. Richard Barker Harrison Ltd. Speswhite China clay product specification. http://www.rbhltd.com/china-clay-kaolin-suppliers/ (2016). Accessed 15 Dec 2016

27. Atkinson, J.H., Richardson, D., Robinson, P.J.: Compression and extension of $K_{0}$ normally consolidated Kaolin clay. J. Geotech. Eng. 113, 1468-1482 (1987). doi:10.1061/ (ASCE)0733-9410(1987)113:12(1468)

28. Ling, F.N.L., Kassim, K.A., Karim, A.T.A.: Size distribution analysis of Kaolin using laser diffraction technique. Adv. Mater. Res. 341-342, 108-112 (2012). doi: 10.4028/www.scientific.net/AMR. 341-342.108

29. Clarke, S.D., Fay, S.D., Warren, J.A., Tyas, A., Rigby, S.E., Reay, J.J., Livesey, R., Elgy, I.: Geotechnical causes for variations in output measured from shallow buried charges. Int. J. Impact Eng. 86, 274-283 (2015). doi:10.1016/j.ijimpeng.2015.08.009

30. Clarke, S.D., Fay, S.D., Warren, J.A., Tyas, A., Rigby, S.E., Reay, J.J., Livesey, R., Elgy, I.: Predicting the role of geotechnical parameters on the output from shallow buried explosives. Int. J. Impact Eng. 102, 117-128 (2017). doi:10.1016/j.ijimpeng.2016.12.006

31. Tyas, A., Watson, A.J.: An investigation of frequency domain dispersion correction of pressure bar signals. Int. J. Impact Eng. 25(1), 87-101 (2001). doi:10.1016/S0734-743X(00)00025-7

32. Tyas, A., Reay, J.J., Fay, S.D., Clarke, S.D., Rigby, S.E., Warren, J.A., Pope, D.J.: Experimental studies of the effect of rapid afterburn on shock development of near-field explosions. Int. J. Prot. Struct. 7(3), 452-465 (2016). doi:10.1177/2041419616665931 